\title{
PERCEPTIONS OF HIGHER EDUCATION STUDENTS ABOUT THE CONSEQUENCES OF THEIR ACADEMIC EMOTIONS
}

\author{
Fátima Leal \\ Centre for Research in Education and Psychology of University of Évora (PORTUGAL)
}

\begin{abstract}
Higher education students in learning situations are constantly being assaulted with academic emotions. The most part of times, these students are not aware of what they feel while studying or even how much these emotions can affect themselves or their learning process [1]. Thus, academic emotions are important due to the impact they can have on students in learning situations [2]
\end{abstract}

This work aims to know the perception of higher education students about their academic emotions and the consequences of those for students. Qualitative methodology was privileged. 48 Portuguese voluntary higher education students from an interior Portuguese university were interviewed $(50 \%$ women). Ages varied between 18 and 27 years old. NVivo was used to organize the information. Thematic content analysis was used to analyse data [3]

Results showed two different positions: students who considered that what they feel while studying did not affect them and other students who assumed this effect. For these latter subjects, their academic emotions affected them positively and negatively, regarding to cognition; affective aspects; emotional regulation needs, motivational aspects; aspects related with study and learning; academic performance; interpersonal relationships and at the level of their personal changing.

These results contribute to the existing knowledge about academic emotions of higher education students and can be important to the development of structural measures in universities. Also, students and teachers can benefit using these data on their practical academic daily life.

Keywords: Consequences, Academic emotions, Higher education students.

\section{INTRODUCTION}

Academic stuff as learning and studying are emotional enriched because they are properness to emotions arising. Students experience a great variety of emotions in academic settings. Academic emotions are those that are directly connected to academic stuff as learning, classroom instruction and achievement. This domain includes students' achievement emotions experienced in school and university environments and involves not only emotions concerning to accomplishment and failure but also emotions linked to instruction and process of studying [4]. Achievement emotions are emotional experiences directly associated to achievement events or achievement outcomes [5] with contexts or even academic situations as classroom scenes and exams taking [6]. In general, achievement emotions can be conceptualized as traits or states emotions and tend to be organized according to specific domains [7][8].

According to [4], it may be assumed that emotions can influence students at a cognitive level, their performance, as well as their physical and mental health. On one hand, positive emotions like enjoyment, hope, and pride can foster students' motivation to learn, their attention, the use of deep learning strategies, and their academic achievement. On the other side, negative emotions such as anxiety, anger, and boredom can negatively compromise learning [9][10].

However, not even higher education students are aware about what they feel while studying or even how much these emotions can affect themselves [1]

The understanding of the academic emotions and their effects on students is crucial for emerging emotionally learning environments that can boost not only the good students' performance but also their psychological wellbeing [11].

\section{METHODOLOGY}

The main objective of this investigation is to understand the perception of higher education students about the consequences of their academic emotions for themselves. 
Qualitative research was the selected one. It is a method that explains phenomena founded on the participants perspectives, finds multiple realities, and builds whole understanding of the occurrences within a context [12]. A properly using of qualitative data analysis can lead to a deeper understanding of the situation once it looks for the relationship between categories and themes of data [13].

The sample involved 48 voluntary Portuguese higher education students with ages between 18 and 27 years old. 24 boys and 24 girls. Interview was the selected technique to collect data. Data was organized with NVivo12 and was analysed according to thematic content analysis [3].

\section{RESULTS}

For parsimonious reasons, we will only present the main results we found.

Asking to students the question "Do you think that what you feel when you are studying affect you?" it was possible to understand if students considered that these experiences had affected them or not. On the other hand, we found in what aspects students referred to be affected - consequences of their emotional experiences.

\subsection{Emotions while studying do not affect}

From the 48 interviewed subjects, 7 students have considered that what they feel when they are studying does not affect them and 41 students considered that what they feel when they are studying, affect them.

\subsubsection{Emotions while studying do not affect}

From the 7 students who answered that what they feel while studying did not affect them, we found 3 different explanations: the ability and capacity to maintain concentration on the task, emotions as a temporary thing and the perception about the value of the task.

The capacity for being concentrated on the task has to do with the ability to control themselves and concentrate in a way that they do not allow that affective experiences can affect them. This capacity allows them to keep focused on tasks even that they can be interrupted.

"normally (...) I am concentrated, I am studying, I am here (...) it is like my brain was divided .... and when one of them is active the other one is closed, so, I always try to differentiate things... so, it doesn't affect me in anyway" (S.5)

"(...) when I start, I think that I am totally focused on that... I am really concentrated... I never deviate very much of what I am doing ... only if there is a big distraction... an environmental distraction ... if someone comes to my room and starts to talk to me and after... ok, ok, but after this, I turn over back to study (...) just for that thing "No! I will do this; I will finish it ..." (S.19)

Emotions as temporary things were verbalized by students that consider that what they feel when they are studying are brief affective experiences and because of that this kind of momentary experiences do not affect them.

"Because they are things on that moment... I do study, and I feel well while I am doing it, but after, I turn back to my life and this are not things that affect me ... they don't have a big impact... although I feel well and realized, it does not affect myself" (S.9)

"(...) sometimes I think "what a hell! Is this that I really want for my life?" because... I start looking to things and they tell me nothing (...) those feelings that I have, and they let me angry (...) but, after, this moment goes away and I don't keep these things" (S.27)

The perception about the value of the task emerged on the speech of one student who considers that what he feels when he is studying does not affect him because he knows the value and importance of the issues for his future

"Because I know that I have to learn that issue not only for evaluations but also for have knowledge that can be necessary to the future" (S. 8) 


\subsection{Emotions while studying do affect}

From 41 students who referred that what they feel while studying affected them, we found eight different aspects: cognitive aspects, affective aspects, emotional regulation, motivational aspects, study and learning aspects related, global personal changing, academic performance, and interpersonal relationship.

\subsubsection{Cognitive aspects: attention/ concentration}

What students feel while they are studying affect them on cognitive aspects namely on attention/concentration. On these two examples, students explain that when they have a lot of work, they feel pressure, nervousness and anxiety and those affective experiences led them to a bigger profusion of thoughts, confusion, and bigger difficulty on concentration.

"when I have works to deliver or prepare myself for a test, that nerves me, and this is prejudicial to my studying process because I am not concentrated (...) it is a lot of things... I am thinking... have this and the other one to do...I cannot concentrate myself" (S.3)

"(...) anxiety... because if I am studying, and the feeling that domines me on that moment it is anxiety, it will affect because I am thinking about 20 other things that are not study (...) and this is my first problem" (S.34)

\subsubsection{Affective Aspects}

What students feel while they are studying can affect them in terms of their own affective aspects: humour state and on their emotions/feelings.

Two examples of students that verbalized that their humour state can be affected by what they feel when they are studying: in the first case, when he feels difficulty on study and on the second case if he feels tired.

"it is likely that it affects me all day... my bad humour (...) if I have to study for an exam and

I feel that I am not understanding the issues" (S.20)

"If I have studied too much, I feel bad humour...it is because tiredness" (Suj.22)

Students that refer that what they feel while they are studying affect them in terms of their emotions/feelings, mentioned: nervousness, anxiety/stress, frustration and difficulty and pleasure.

"It affects me (...) if it is an issue in which I am interested (...) I feel pleasure on learning" (S.12)

"I can be happy; I can be studying well committed (...) and I feel proud with my effort" (S.35)

"sometimes we get bored to being there ... always around books and studying" (S.22)

"as I feel nervous when I don't know, I have a lot of ideas and this brings me to more nervousness" (S.4)

"when I have to do work presentation, I feel all that little nervous that accumulates and then it reflects physically" (S.44)

Anxiety aroused in times when students felt pressure because they had to study a lot and they could not understand the issues that they were studying. This anxiety state leads to a mental block that prevents them from reasoning and the ability to study. This state causes a feeling of inability to continue to study.

"if I am not understanding issues even after someone explain me ...if I cannot understand to be able to do the exercises later ... I get really stressed" (S.20)

"because of anxiety, I block...and then it still augments my anxiety (...) I block because I am so much anxious...to do and want to study and want to know and don't be capable to do it... while I am in this state of anxiety ... it is not easy to separate so easily (...)" (S.25)

Anguish emerged on a talk of a student who referred that what he feels when he is not understanding issues lead him to feel anguish.

"affects me...this anguish that I feel when I read one issue and I cannot remember all the names I read (...) if I cannot do it (...) it is anguishing" (S. 15) 
Frustration emerged in relation to a feeling of personal inefficacy to achieve intended goals.

"Affects me ... I get frustrated because I am not able to get my goals" (S.15)

"(...) If I feel that I am not able (...) I feel a little bit frustrated with what I am doing" (S.31)

\subsubsection{Emotional regulation}

Emotional regulation encompasses students' verbalizations related to the need for emotional regulation to later be available to study. It is also evident the importance of maintaining an optimistic and positive aptitude

"if I am very angry, I cannot study and so I always try to calm down myself (...)" (S.32)

"I have to calm down first...smoke some cigarettes and there is... I have to calm down to be able to study" (S.25)

"I always try to contradict this anxiety state with a more positive thought" (S.34)

\subsubsection{Motivational aspects}

What students feel while studying affect students on motivational aspects: to maintain motivation, in a general way, self-realization, motivation to understand, feeling of duty.

"If I am demotivated it affects me because I have no will to study and, in fact, I don' $t$ do it" (S.23)

"If I don't like an issue, I will have less predisposition to try to understand this subject..." (S.12)

"it affects me because when I am interested and I am going to study (...) it is like a game and so, I get more interested, and I can work on it" (S.13)

"If we are fine, and things did well, we have this will, commitment ... another dedication and motivation to continue to study (...)" (S.45)

"it affects me mainly when my emotions are positive ... It makes me feel fine and selfrealized, it makes me feel that I have learned (...) it makes me feel better (...) because I am learning" (S.30)

\subsubsection{Aspects related with study and learning}

What students feel when they are studying can affect them in specific aspects related with study and learning in a general way, in the amount of time expended, on spent effort, on continuity of study, on the quality and study's productivity.

"if I feel calm and relaxed, I am going progressing on reading and on analysis, on observation, and that's why that what I feel on study moments affects me so much on my study process" (S.34)

"Sometimes when we have personal problems, and we are not fine emotionally that reflects on study (...) I feel that things are not working, and I am not understanding, and my academic performance is not ok" (S.26)

"If I feel away from what I am studying and if I am not enthusiastic, it is clear that the study will be less productive (...) It is easier to start thinking about something other than what I am working with." (S.48)

The amount of effort that will be necessary emerged on the speech of a student who considers that when he feels difficulties while he is studying, he needs to make more effort and study much more that what he is doing.

"[when I start studying and feel some difficulty] I will need to study much more... and make a bigger effort (...)" (S.2)

Boring can affect the will to continue studying.

"when it is a feeling of boring or tiredness, this takes me to want to stop to study and look for another activity" (S.41) 
Quality of learning can be affected in a positive way when students are more motivated. On the other hand, it can be negatively affected in case of distraction and difficulties on being focused.

"when we are motivated, I think we learn better (...)" (S.14)

"if I am always distracted and cannot be focused on issues, I won't learn anything in a good way" (S.48)

\subsubsection{Academic performance}

What students feel while they are studying can affect them concerning to academic achievement specifically on their performance in evaluation moments and on their academic performance. There is an association between the like/dislike issues and a low academic performance.

"affects me on my grades... I don't have the notes that I was expecting" (S.21)

"when I am studying and I don't like it, normally, I have a poor academic performance" (S.39)

When students are studying and they like/dislike the class material and feel motivation it can affect them on evaluation moments:

"I think that it will affect my performance on tests or exams ... it will affect my achievement (...) when I like the class material, it is better" (S.36)

"when we are demotivated, it looks like we understand, but, when we get the moment of doing the test, we are out there and after, it looks like we cannot remember anything anymore (...)" (S.14)

\subsubsection{Interpersonal Relationship}

What students feel when they are studying can affect them on an interpersonal relationship level. This happens specially on moments of study in stress situations. These experiences lead to the isolation and avoiding the presence and company of peers.

"it affects me on my relationship with others" (S.40)

"Affects me very much because ... I need to make things the most perfect possible (...) and this puts me away of others ... I get myself alone (...) I need to study, study, study and if I lose my focus, I start thinking that I would not do it (...) this affects me because I distance myself away ... it is me and not them" (S.16)

\subsubsection{Global personal change}

What students feel when they are studying can affect them in altering the way as they perspective their future. This change can be influenced by doubts about their own capacities and knowledge, interfering with their future choices - a global personal change.

"Hum ...I think "yes" it affects me on my personal life" (S.44)

Through self-questioning, students reflect about themselves, about their academic and professional future.

"It affects me, because I ask myself ... (...) at the beginning my ego very small, I criticize myself a lot... I am always questioning myself... and this is bad ... this affects me because this provokes me a bad humour ... I am conscious that I don't understand anything about that theme... and then this reflects, and I take it for all the things I do" (S.46)

"It affects because it makes me think about my future... what I would do and how it would be my life in a couple of years..." (S.23)

"If I have some doubts and if there is some question where I realize that I don't know, I think I am not intelligent enough and I don't have experience to explain that issue, then it makes think about my paths... If I did right choice, If I am in the right way, and after, all this reflects on my life... and this is very stressful because I cannot separate Academic study from the rest of my things ...there is no limit between them" (S.44) 


\section{CONCLUSIONS}

Analysing students' answers to the question "do you think that what you feel when you are studying affect you?" it was possible to understand, on one hand, their perception about the consequences of what they feel while they are studying for themselves, and on the other hand, what were those affected aspects.

We found two groups of students: the first one who have considered that what they feel while studying do not affect them and another group that have considered that what they feel while studying affected them. The latter was more represented than the former.

Those students that have considered that what they feel while studying did not affect them, justified it by their capacity to maintain focused and concentrated on study; by their perspective about their own emotions and by their perspective about their own emotions and the value they attributed to the task. These results are curious because it is not frequent that individuals do not consider that what they feel can affect them. It is intriguing and it could be interesting to understand better these individuals and their characteristics.

Relating to the other group of students and the affected aspects, we have identified cognitive aspects, affective aspects, emotional regulation needs, motivational aspects, study and learning aspects related, global personal changing, academic performance and interpersonal relationship.

Concerning to affective aspects, emotions like nervousness, anxiety, and stress raised in heavy workload situations and moments of evaluation. Also, in situations where students do not like matters, they are unable to study the whole subject, and when they feel difficulties to understand issues.

This research brings us new data once, from what we know, there are no studies asking students about their perception relating to the consequences of what they feel while studying.

These findings can be relevant for several higher education intervenient as peers, teachers, staff, and other professionals that can have an active role if they are aware of the difficulties that some students can be experiencing and if they are not able to deal with those problems.

Some intervention strategies can include a simple talk with a psychologist, a tutoring system, inclusion in an interesting task, or other procedures like participating in collaborative learning groups, grouped intervention programs, or even individualized psychological counselling.

\section{ACKNOWLEDGEMENTS}

This work is supported by Portuguese national funds through the FCT - Fundação para a Ciência e a Tecnologia, I.P., under the project Learning and Teaching at University, PTDC/CED-EDG/29252/2017.

\section{REFERENCES}

[1] F. Leal and L. Grácio. "Aspetos afetivos e regulatórios durante o processo de estudo de estudantes do ensino superior" In Educar hoje: Diálogos entre psicologia, educação e currículo (V. Monteiro, L. Mata, M. Martins, J. Morgado, J. Silva, A. Silva and M. Gomes (Orgs.). pp. 85-103. Lisboa: Edições ISPA, 2019.

[2] J.M. Harley, R. Pekrun, J.L. Taxer and J.J. Gross, "Emotion regulation in achievement situations: An integrated model" Educational Psychologist, vol. 54, no. 2, pp. 106-126, 2019.

[3] L. Bardin, Análise de conteúdo. Lisboa, Portugal: Edições 70, 2008.

[4] R. Pekrun, T. Goetz, W. Titz and R. P. Perry, "Academic Emotions in Students' Self-Regulated Learning and Achievement: A Program of Qualitative and Quantitative Research" Educational Psychologist, vol.37, no. 2, pp. 91-105, 2002.

[5] R. Pekrun, "The Control-Value Theory of Achievement Emotions: Assumptions, Corollaries, and Implications for Educational Research and Practice". Educational Psychology Review, vol. 18, pp. 315-341, 2006.

[6] T. Goetz, F. Preckel, R. Pekrun, and N. C. Hall, "Emotional experiences during test taking: Does cognitive ability make a difference?", Learning and Individual Differences, vol.17, no. 1, pp.3-16, 2007. 
[7] T. Goetz, A.C. Frenzel, R. Pekrun, N.C. Hall, and O. Lüdtke, "Between and within Domain Relations of Students' Academic Emotions", Journal of Educational Psychology, vol. 99, pp. 715-733, 2007.

[8] T. Goetz, R. Pekrun, N. Hall, and L. Haag, L. "Academic Emotions from a Social-Cognitive Perspective: Antecedents and Domain Specificity of Students' Affect in the Context of Latin Instruction", British Journal of Educational Psychology, vol. 76, pp. 289-308, 2006.

[9] J. M. Dewaele, J. Witney, K. Saito, and L. Dewaele, "Foreign language enjoyment and anxiety: The effect of teacher and learner variables" Language Teaching Research, vol. 22, no. 6, pp. 676 - 697, 2018.

[10] R. Pekrun, and R.P. Perry, "Control-value theory of achievement emotions". In Educational psychology handbook series. International handbook of emotions in education, R. Pekrun and L. Linnenbrink-Garcia (Eds.) pp. 120-141. Routledge/Taylor \& Francis Group, 2014.

[11] K. Shao, R. Pekrun, H.W. Marsh, and K. Loderer, "Control-value appraisals, achievement emotions, and foreign language performance: A latent interaction analysis". Learning and Instruction, vol. 69, pp. 1-12, 2020.

[12] C. D. Glickman, S. P. Gordon, and J. Ross-Gordon, Supervision and Instructional Leadership: A Developmental Approach, Pearson, (7ed.) 2007.

[13] A.H. Hilal, and S.S. Alabri, "Using NVivo for data analysis in qualitative research". International Interdisciplinary Journal of Education, vol. 2, pp. 181-186, 2013. 